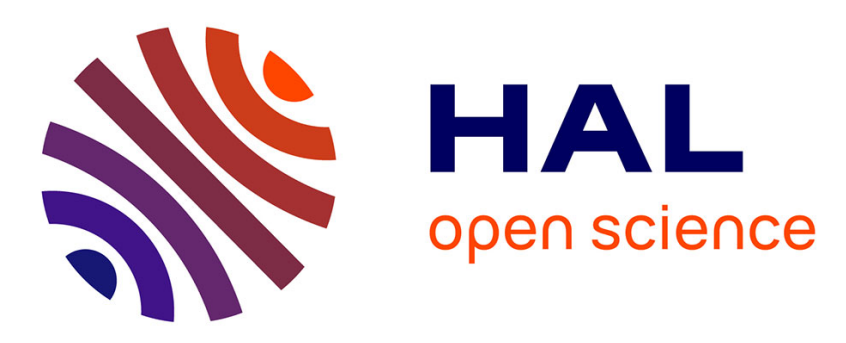

\title{
Diffuse Neutron Scattering of the High Temperature Phase of Fe3O4
}

\author{
K. Siratori, Y. Ishii, Y. Morii, S. Funahashi, A. Yanase
}

\section{To cite this version:}

K. Siratori, Y. Ishii, Y. Morii, S. Funahashi, A. Yanase. Diffuse Neutron Scattering of the High Temperature Phase of Fe3O4. Journal de Physique IV Proceedings, 1997, 07 (C1), pp.C1-585-C1-586. 10.1051/jp4:19971240 . jpa-00254926

\section{HAL Id: jpa-00254926 https://hal.science/jpa-00254926}

Submitted on 1 Jan 1997

HAL is a multi-disciplinary open access archive for the deposit and dissemination of scientific research documents, whether they are published or not. The documents may come from teaching and research institutions in France or abroad, or from public or private research centers.
L'archive ouverte pluridisciplinaire HAL, est destinée au dépôt et à la diffusion de documents scientifiques de niveau recherche, publiés ou non, émanant des établissements d'enseignement et de recherche français ou étrangers, des laboratoires publics ou privés. 


\title{
Diffuse Neutron Scattering of the High Temperature Phase of $\mathrm{Fe}_{3} \mathrm{O}_{4}$
}

\author{
K. Siratori, Y. Ishii*, Y. Morii*, S. Funahashi** and A. Yanase*** \\ Department of Physics, Faculty of Science, Kyushu University, Fukuoka 812-81, Japan \\ * Japan Atomic Energy Research Institute, Tokai, Ibaraki 319-11, Japan \\ ** Institute for Solid State Physics, University of Tokyo, Minato, Tokyo 106, Japan \\ *** College of Integrated Arts and Sciences, University of Osaka Prefecture, Sakai, Osaka 593, Japan
}

\begin{abstract}
Diffuse neutron scattering is observed for the high temperature phase of magnetite, $\mathrm{Fe}_{3} \mathrm{O}_{4}$, in an extended range in the (001) and (011) plane of the Brillouin zone. Contours of scattered intensity shows a characteristic pattern, discs in the (100) plane around the $\Gamma$ points, spheres around the $X$ points, etc. The intensity of this diffuse scattering increases with decreasing temperature down to the Verwey point and is attributed to the lattice distortion induced by charge fluctuation in the B site, or polarons. Symmetry and the polarization of the atomic displacement are discussed on the observation.
\end{abstract}

\section{INTRODUCTION}

Details of the low temperature transition of magnetite, so called Verwey transition, have not been elucidated after about 70 years from discovery [1]. The model of the transition started from the order-disorder transformation of $\mathrm{Fe}^{2+}$ and $\mathrm{Fe}^{3+}$ ions in the $\mathrm{B}$ site, where electrons were assumed localized, and the deformation of the lattice was ignored.[2] Importance of the kinetic energy of $3 d$ electrons was suggested first by Mott [3] and supported by the structure-insensitiveness of the transport phenomena in the high temperature phase[4], decrease of the transition temperature by compression[5], band structure calculation[6] and detailed photoemission experiment[7]. Increase of the Verwey temperature by $6.1 \mathrm{~K}$ in a crystal in which $43 \%$ of oxygen atoms are replaced by ${ }^{18} \mathrm{O}$ confirmed the crucial roles of phonons[8]. The characteristic frequencies of the charge fluctuation and the lattice deformation were estimated as $\sim 10^{12} \mathrm{~Hz}$, by both nuclear magnetic relaxation[9] and neutron inelastic scattering [10] experiments, respectively. Thus, the Verwey transition in $\mathrm{Fe}_{3} \mathrm{O}_{4}$ is to be considered as the phase change of an assemblage of charges accompanied by lattice deformation, or polarons, with more or less itinerant character.

The aim of the present investigation is to make the structure of the polaron clear from the diffuse scattering of neutrons in the high temperature phase. Shapiro, Iizumi and Shirane[10] reported neutron diffuse scattering in as early as 1976. They have not given, however, analysis of the scattering intensities in the whole reciprocal space.

\section{EXPERIMENTAL PROCEEDURES AND RESULTS}

A single crystal of $\mathrm{Fe}_{3} \mathrm{O}_{4}$, about $12 \mathrm{~mm}$ in diameter, was grown by Bridgeman method in $\mathrm{CO}_{2}$ atmosphere. The growth direction was tilted from either of the principal axes. Two ends were cut parallel to the (001) and (011) planes, respectively, and the center of the crystal of about $25 \mathrm{~mm}$ in length was used for the measurements. The specimen was annealed in the controlled atmosphere of $\mathrm{CO}-\mathrm{CO}_{2}$ mixture to achieve stoichiometry. Then it was annealed at $700^{\circ} \mathrm{C}$ for 1 week in an evacuated quartz tube, to eliminate possible internal strains.

Neutron scattering measurements were performed by the use of a triple-axis spectrometer, TAS-1, installed at JRR-3M, JAERI-Tokai. The incident neutron energy was $41.03 \mathrm{meV}$ and collimators were set as $40^{\circ}-40^{\prime}-40^{\circ}-40^{\prime}$. Scattering intensity was measured in a wide range of the (001) and (011) planes, by the mesh of $\Delta q=0.1$. The background was about 350 neutrons per $150 \mathrm{~s}$. In the measurements, contamination due to the $\lambda / 2$ components of incident neutrons and polycrystalline $\mathrm{Al}$ of the sample holder could not be avoided. Note that the intensities of the Bragg spots were of the order of $10^{6}-10^{7}$ at the above experimental conditions. Intensities at ( 820$)$, etc., due to the $\lambda / 2$ components, were simply ignored. Halos due to the holder were calculated on an assumption that they are homogenous with Gaussian profile and subtracted from the raw data.

Figure 1 shows contours of 200 counts per 150 s, starting at 450 counts, in the (001) and (011) planes, measured at $125 \mathrm{~K}$. The Lorentz factor was assumed as $\sin (2 \theta)$. In the $(001)$ plane, there are scatterings at $\mathrm{X}$ points with circular contour and streaks between some of the $X$ points, in addition to those around (800) and (840). According to the results in the (011) plane, scattering around the $\mathrm{X}$ points shows a tendency to extend along the edge of the Brillouin zone. It was observed that the decrease of the diffuse scattering intensity with increasing temperature, up to $250 \mathrm{~K}$, is the same for all of them. Scattering as a whole, not some part only, should be considered. According to Shapiro et al. [10], this diffuse scattering is quasi-elastic. 

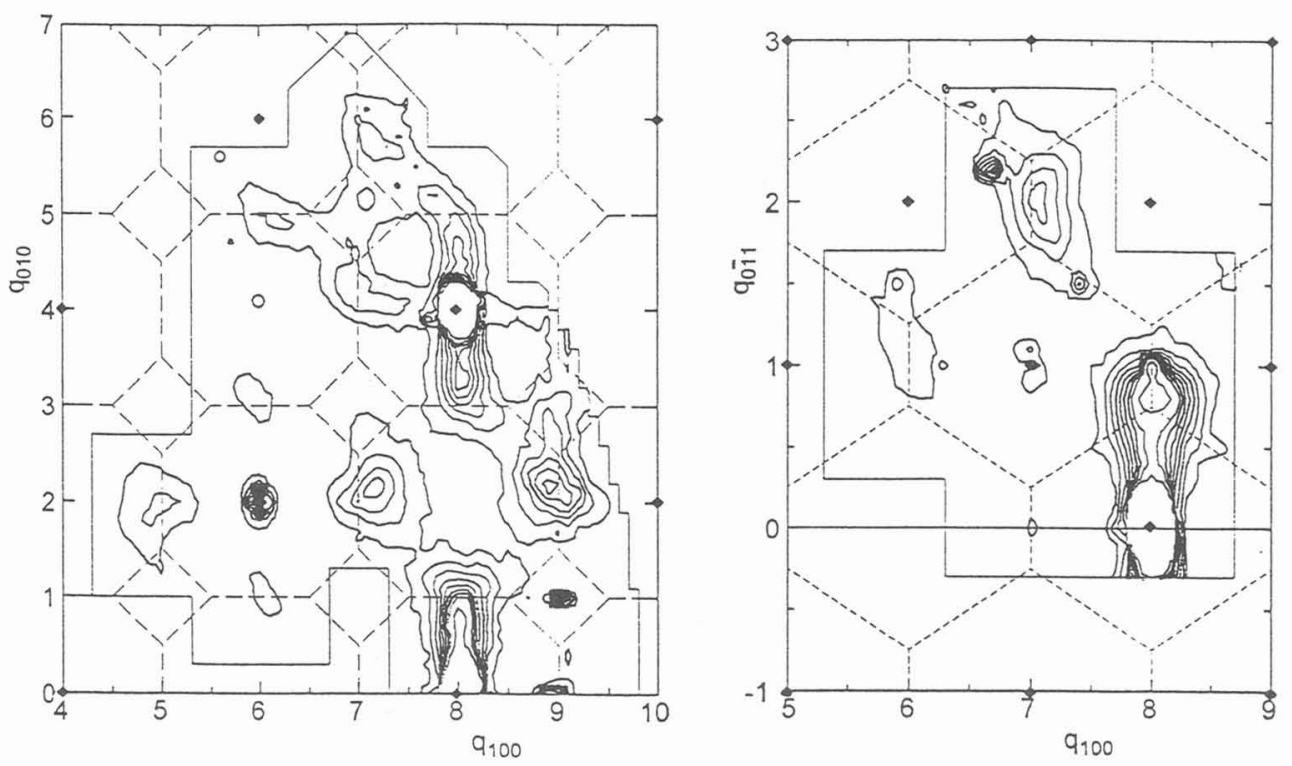

Fig. 1 Contour of the scattered neutron intensity in the (001) (left hand side) and (011) (right hand side) planes, at $125 \mathrm{~K}$. The lowest contour is for 450 counts per $150 \mathrm{~s}$ and the difference between adjacent contours is 200 counts/150 s. Fine lines are the boundary of measured regions and broken lines indicate Brillouin zone boundaries.

\section{DISCUSSION}

The intensity of the diffuse scattering at point $q$ in the Brilliouin zone is proportional to,

$$
I_{c}=\left|\sum_{\lambda} \sum_{j} A(\lambda, \mathbf{q}) \cdot F(\mathbf{s}, j) \cdot[\mathbf{s} \cdot \mathbf{e}(\lambda, \mathbf{q}, j)]\right|^{2} \text {. }
$$

Here, $\mathrm{j}$ assigns atoms in the 'unit cell, $\lambda$ assigns phonon modes, $s$ is the scattering vector, $A$ is the amplitude of the phonon, $F$ is the structure factor and $e$ is the displacement vector of the atom $\mathrm{j}$ for the phonon $\lambda, q$. We will start from an assumption that the symmetry of the phonon active for the polaron formation can be uniquely determined.

Observed $X$ point intensities show following characteristics:

1. Intensities around $(620)$ increase in the order of $(610)$ and $(630),(520),(720)$ : the character of longitudinal phonons.

2. Around (800) and (840), especially (700), intensities are much weaker than the above, except (810) and (830).

3. Intensity of (722) is about 2.5 times larger than (611).

According to the symmetry consideration, there are four kinds of phonons at the $\mathrm{X}$ point: $\mathrm{X}_{1}, \mathrm{X}_{2}, \mathrm{X}_{3}$ and $\mathrm{X}_{4}$. Of these, all the components of $X_{2}$ are transverse phonons and this mode can be ignored because of point 1 above. Longitudinal phonons with $\mathrm{X}_{1}$ symmetry should give finite intensity at (700) and are discarded due to point 2 . To explain point 3 , not only the longitudinal oscillation of oxygen but also of the B site iron should be taken into account. This is possible only for the phonons with $\mathrm{X}_{3}$ symmetry which has 2 longitudinal modes for both oxygen and the $\mathrm{B}$ site iron atoms.

Scattering along the $\Delta$ axis is apparently due to transverse acoustic phonons, belonging to the $\Delta_{5}$ symmetry. However, intensity decreases from (800) to (840). This means that the displacement cannot be purely transversal but increase of the longitudinal components should be assumed from $\Gamma$ to $X$. Note that $\Delta_{5}$ changes into $X_{3}+X_{4}$ at the $X$ point.

A full report will appear elsewhere.

\section{References}

[1] R.W.Miller: J. Amer. Chem. Soc 51 (1929) 215; F.Okamura: Sci. Rep. Tohoku Univ. (I) 21 (1932) 231.

[2] E.J.Verwey, P.W.Haayman and F.C.Romeijn: J. Chem. Phys. 15 (1947) 181.

[3] N.F.Mott: Adv. Phys. 16 (1967) 49.

[4] A.J.M.Kuipers and V.A.M.Brabers: Phys. Rev. B14 (1976) 488.

[5] G.A.Samara: Phys. Rev. Lett. 21 (1968) 795; Y.Kakudate, N.Môri and Y.Kino: J. Magn. Magn. Mat. 12 (1979) 22.

[6] A.Yanase and K.Siratori: J. Phys. Soc. Jpn. 53 (1984) 312.

[7] A.Chainani, T.Yokoya, T.Morimoto, T.Takahashi and S.Todo: Phys. Rev. B51 (1995) 17976.

[8] E.I.Terukov, W.Reichelt, D.Ihle and H.Oppermann: Phys. Status Solidi b95 (1979) 491.

[9] T.Mizoguchi and M.Inoue: J. Phys. Soc. Jpn. 21 (1966) 1310.

[10] S.M.Shapiro, M.lizumi and G.Shirane: Phys. Rev. B14 (1976) 200. 